\title{
The consistency between writing self-efficacy and writing performance
}

\begin{abstract}
This study aimed to evaluate the consistency between tertiary learners' writing self-efficacy and writing performance evaluation in academic writing in order to understand the tertiary students' self-efficacy phenomena in learning to write. Two measurements were analysed and compared namely the learners' writing self-efficacy scales and learners' writing performance. Basically, it is a case study where 33 UPM students participated in the research for four months. In this study, the learners' writing self-efficacy was assessed based on the writing self-efficacy (WSE) scale adapted from Bottomley, Henk \& Melnick (1997), while, the document analysis was based on the students' writing performance throughout the four months. Overall, this study did not mainly based on the score of WSE scales only but also looked from the angle of the students' writing performance by looking at writing skills in detail namely content, organization, grammar, vocabulary and mechanic of writing. Here, the analysis of the essay and rating was done from the perspective of Jacobs, Zinkgraf, Wormuth, Hartfiel, \& Hughey (1981) and adapted by Hedgcock and Lefkowitz (1992). In order to plot the consistency and trend of the two measurements (WSE and writing skills), ratio and Chisquare analysis were carried out using SPSS program. Findings showed that the distribution of writing skills performance vary depending on the self-efficacy level (i.e. high, average and low self-efficacy level).
\end{abstract}

Keyword: Writing skills; Writing self-efficacy level; Tertiary learners 